University of Nebraska - Lincoln

DigitalCommons@University of Nebraska - Lincoln

October 2006

\title{
The Effects of Victim's Substance Use and Relationship \\ Closeness on Mock Jurors' Judgments in an Acquaintance Rape Case
}

Ashley A. Wenger

University of Nebraska-Lincoln

Brian H. Bornstein

University of Nebraska-Lincoln, bbornstein2@unl.edu

Follow this and additional works at: https://digitalcommons.unl.edu/psychfacpub

Part of the Psychiatry and Psychology Commons

Wenger, Ashley A. and Bornstein, Brian H., "The Effects of Victim's Substance Use and Relationship Closeness on Mock Jurors' Judgments in an Acquaintance Rape Case" (2006). Faculty Publications, Department of Psychology. 190.

https://digitalcommons.unl.edu/psychfacpub/190

This Article is brought to you for free and open access by the Psychology, Department of at DigitalCommons@University of Nebraska - Lincoln. It has been accepted for inclusion in Faculty Publications, Department of Psychology by an authorized administrator of DigitalCommons@University of Nebraska - Lincoln. 


\title{
The Effects of Victim's Substance Use and Relationship Closeness on Mock Jurors' Judgments in an Acquaintance Rape Case
}

\author{
Ashley A. Wenger \& Brian H. Bornstein \\ Department of Psychology, University of Nebraska-Lincoln
}

Published online October 27, 2006

\begin{abstract}
Previous research has demonstrated that jurors perceive a female victim who is drunk at the time when she is sexually assaulted as less credible and more deserving of such punishment than a sober victim. In this experiment, we investigated the effect of an alleged acquaintance rape victim's type of substance use and closeness of relationship with the defendant on the judgments of 152 student mock jurors. Participants read a case summary and answered a series of questions about their impressions of the actors and actions involved in the case. Participants perceived a victim who was sober at the time of the incident as more credible than a victim who was intoxicated due to illegal substance use (alcohol or LSD), and convictions were also most likely when the victim was sober. Women perceived the victim as more credible than men did. Higher victim credibility judgments were associated with less rape myth acceptance (RMA) on the part of participants.
\end{abstract}

Keywords: Juries, Rape, Substance use

An alarming proportion of college women surveyed in the United States report having fallen victim to some form of sexual coercion; estimates range as high as 50\% (e.g., Abbey, 2002; Copenhaver \& Grauerholz, 1991; Ullman, Karabatsos, \& Koss, 1999). In addition, up to $25 \%$ of college men admit having committed some form of sexual assault since age 14 (Abbey, 2002). A clear correlation exists between sexual assault and alcohol use by victims (Abbey, Clinton, McAuslan, Zawacki, \& Buck, 2002; Abbey, Zawacki, Buck, Clinton, \& McAuslan, 2004; Seifert, 1999; Testa \& Parks, 1996; Tyler, Hoyt, \& Whitbeck, 1998; Ullman et al., 1999). For example, of the 132 sexual assault victims sur- veyed by Abbey (Abbey, 2002), 40\% reported that they had consumed alcohol prior to or during the interaction, and $55 \%$ reported that the perpetrator had consumed alcohol.

Substance use and sexual assault

The mechanism by which alcohol consumption by victims leads to sexual victimization is unclear (Abbey et al., 2004; Testa \& Parks, 1996), but it is associated with less victim resistance (Abbey et al., 2002). The effect of drinking on victim resistance may be indirect; for example, Ullman, Karabatsos, and Koss (Ullman et al., 1999) found that it is mediated by decreased offender aggression. Studies have also demonstrated that victims of alcohol-related sexual assaults report using alcohol on a more frequent basis than do nonalcohol-related assault victims and nonvictims (Abbey et al., 2004; Marx, Nicols-Anderson, Messman-Moore, Miranda, \& Porter, 2000; Testa \& Parks, 1996). Compared to nonvictims and victims of nonalcohol-related assaults, alcohol-related assault victims also demonstrate an increased tendency to endorse alcohol expectancies, such as a belief in alcohol's ability to increase social ability and power and to decrease sexual inhibition (Abbey et al., 2004; Marx et al., 2000).

Alcohol use can also change the manner in which others, such as police and potential jurors, view the dynamics involved in a sexual assault. Alcohol consumption (by both men and women) is associated with a perception of sexual availability and willingness (George, Lehman, Cue, \& Martinez, 1997). In general, if sexual assault victims fail to achieve "legitimate victim status," guilty verdicts are less likely (Kos$\mathrm{ki}, 2002$ ); victim substance use is one factor that is likely to 
detract from the victim's status. For example, female victims tend to be viewed as less credible, and held more accountable, if they were intoxicated rather than sober at the time of the assault (Hammock \& Richardson, 1997; Schuller \& Wall, 1998). Intoxicated victims are viewed as more "deserving" of such punishment because they had placed themselves in a high-risk situation. Schuller and Wall (1998) reported an interaction between victim and defendant alcohol use, such that an intoxicated rape defendant was more likely than a sober defendant to be found guilty but only when the victim had also consumed alcohol (see also Wall \& Schuller, 2000). This pattern suggests the existence of a complex interplay between the victim's and the perpetrator's substance use, with some evidence of a double standard for men and women in regard to the social acceptability of drinking (Leigh, Aramburu, \& Norris, 1992).

Previous research on the perception of intoxicated sexual assault victims has focused on alcohol use (Hammock \& Richardson, 1997; Schuller \& Wall, 1998; Wall \& Schuller, 2000), but the general population views alcohol differently from other psychoactive substances. For example, one largescale questionnaire study showed that over $55 \%$ of the respondents perceived the physical harm from alcohol and marijuana use to be comparable (Weisheit \& Johnson, 1992), but this relatively receptive and accepting response differed distinctly from the responses given to drugs such as heroin, LSD, and cocaine. Over $84 \%$ of the survey respondents rated use of these substances as being more harmful than use of alcohol (Weisheit \& Johnson, 1992). Another survey showed that, although most participants classified occasional use of LSD to be a serious crime, they merely "discouraged" the daily use of marijuana and alcohol (Stylianou, 2002).

In light of the differential attitudes toward alcohol and other types of substances (Weisheit \& Johnson, 1992), as well as the widespread use of these other substances (e.g., $5-10 \%$ of high school seniors admit to having used LSD at least once; Doweiko, 1996), it seems worthwhile to explore how sexual assault victims intoxicated by other means would be perceived. If "blaming the victim" occurs for a victim who has consumed a relatively unstigmatized substance such as alcohol, then intoxication from consumption of less socially acceptable substances should elicit even more negative perceptions of the victim. In addition, women's drug use predicts violent victimization even more strongly than women's drinking does (Kilpatrick, Acierno, Resnick, Saunders, \& Best, 1997; Testa, 2004). This fact further justifies the importance of exploring the role of substances other than alcohol in perceptions of sexual assault.

Relationship closeness and sexual assault

Another variable that has an impact on perceptions of both the victim and the assailant in a sexual assault is the re- lationship between them. Perceptions of stranger rape and acquaintance rape differ considerably; greater blame is generally attributed to the victim when she knows her assailant (e.g., Frese, Moya, \& Megías, 2004; George \& Martinez, 2002; Schuller \& Klippenstine, 2004). Furthermore, not all types of acquaintance are treated equally: The relational history between the victim and the perpetrator matters as well. A preexisting romantic relationship, especially if it has involved sexual relations, leads to harsher judgments of the victim in cases of alleged sexual assault (Schuller \& Klippenstine, 2004). The effect of relationship type can be moderated by victim substance use. For example, Hammock and Richardson (Hammock \& Richardson, 1997) found that an intoxicated sexual assault victim was perceived as more responsible than a sober victim when the relationship between the defendant and victim was not close, but when the defendant and victim were close (i.e., previously dating), the pattern reversed. In this situation, the victim was seen as less responsible (and the defendant was viewed as more responsible) when the victim was intoxicated than when she was sober (Hammock \& Richardson, 1997). Thus, the nature of the relationship appears to create expectancies about what sorts of behavior are appropriate: If a man assaults a new acquaintance after getting her drunk, then she is at fault, presumably for having put herself in that position; but if a man assaults a romantic partner (e.g., girlfriend, fiancée) after getting her drunk, then he is at fault, presumably for having violated her trust.

Although previous researchers have addressed the interaction of relationship closeness with alcohol consumption (Hammock \& Richardson, 1997), they have not investigated its possible interaction with other substances. As noted earlier, alcohol is viewed as a relatively "safe" drug that is associated with different attitudes and expectancies than other drugs are (Stylianou, 2002; Weisheit \& Johnson, 1992). In the present study, we examined whether the relationship between substance use and relationship closeness is the same for LSD, a drug that is less socially acceptable than alcohol but still somewhat widely used.

Experimental overview and hypotheses

We investigated the effects of different types of substance intoxication and closeness of victim-assailant relationship on mock jurors' perceptions of an acquaintance rape victim in a simulated trial context. The experimental conditions manipulated the substance with which the victim had become intoxicated at the time of the assault. Conditions varied in substance and legality among (a) sober/control condition, (b) legal alcohol intoxication, (c) illegal (underage) alcohol intoxication, and (d) LSD intoxication. LSD was chosen because it is perceived as a much more dangerous, and less acceptable, sub- 
stance than alcohol (as opposed to, say, marijuana, the perception of which does not differ consistently from alcohol Stylianou, 2002; Weisheit \& Johnson, 1992). Both the legal and illegal alcohol conditions were included in an attempt to determine the extent to which any negative perceptions of the victim were due to her use of an intoxicating substance (true in all but the sober condition), as opposed to her use of a substance that was intoxicating as well as illegal (true in the illegal alcohol and LSD conditions). The defendant had either been dating the victim or was a first-time acquaintance of the victim.

We had three main hypotheses. First, based on previous research (Hammock \& Richardson, 1997; Schuller \& Wall, 1998), we hypothesized that mock jurors would perceive victims who were sober as most credible, followed by victims who were intoxicated as a result of legal alcohol, then victims intoxicated due to illegal alcohol use; we predicted further that victims who were intoxicated as a result of LSD use would be viewed as least credible, given the low opinion that most people have of LSD (Stylianou, 2002; Weisheit \& Johnson, 1992). Second, we hypothesized that relationship closeness would interact with the victim's level of intoxication. Victim-perpetrator relational history influences perceptions of the situation (Schuller \& Klippenstine, 2004) and can moderate the effect of other factors, such as rape myth acceptance (RMA) (Frese et al., 2004) and the victim's substance use (Hammock \& Richardson, 1997). Specifically, when the relationship between the defendant and victim was not close, we predicted that defendants would be held less culpable when the victim was intoxicated than when she was sober. However, when the relationship was close and the victim was intoxicated, we predicted a pattern reversal, where the defendant would be viewed as more culpable at the time of the sexual assault. The leading explanation for this effect is that observers blame an intoxicated victim for putting herself at risk by voluntarily consuming a psychoactive substance (Hammock \& Richardson, 1997; Schuller \& Wall, 1998); thus, we expected that the effect would be even stronger for a stigmatized drug such as LSD than it would be for alcohol.

Third, we investigated the relationship between participants' trial judgments and their beliefs about issues relevant to the case, such as rape, alcohol, and drug use. Past research has shown that individuals' beliefs about alcohol-related behavior and sexual assault influence sexual assault perpetration (Abbey, McAuslan, Ross, \& Zawacki, 1999; Abbey et al., 2004; Zawacki, Abbey, Buck, McAuslan, \& Clinton-Sherrod, 2003). These attitudes, especially the acceptance of rape myths, also predict others' evaluations of persons involved in coercive sexual encounters. For example, RMA is correlated with perceptions of victim and perpetrator credibility, as well as jurors' judgments in a mock rape trial: Specifically, individuals high in RMA find victims less credible, perpetrators more cred- ible, and are less likely to convict (Deitz, Littman, \& Bentley, 1984; Frese et al., 2004; Jimenez \& Abreu, 2003; Koski, 2002; Lonsway \& Fitzgerald, 1994; Wall \& Schuller, 2000).

Mock jurors' attitudes toward women and gender roles matter as well. Abrams et al. found that individuals high in benevolent sexism evaluated a rape victim as more blameworthy (Abrams, Viki, Masser, \& Bohner, 2003), and a rape perpetrator as less blameworthy (Viki, Abrams, \& Masser, 2004), than less sexist individuals did. To determine participants' relevant belief systems, the Rape Myth Acceptance Scale (RMAS; Burt, 1980), Ambivalent Sexism Inventory (ASI; Glick \& Fiske, 1996), and Cognitive Appraisal of Risky Events questionnaire (CARE; Fromme, Katz, \& Rivet, 1997) were included. Higher levels of RMA and stronger sexist beliefs, as indicated by these measures, were expected to correlate with lower ratings of victim credibility and with acquittals.

The inclusion of the CARE measure was somewhat more exploratory. Previous researchers have not examined the relationship between jurors' risk-taking attitudes and their decisions. Attitudes toward risky behaviors-especially drug and alcohol use, aggression, or unprotected sex-might reasonably be associated with one's evaluation of a situation that includes these behaviors. However, the exact nature of any such relationship is unclear. On the one hand, jurors who engage in (or have positive attitudes toward) risky behaviors themselves might be more sympathetic toward a defendant who allegedly committed a drug-or alcohol-involved sexual assault (i.e., a similarity-leniency effect); on the other hand, high juror-defendant similarity sometimes leads to harsher judgments (i.e., a "black sheep" effect). The nature of such effects is inconsistent and complex (Taylor \& Hosch, 2004).

Previous research has also identified gender as one of the strongest predictors of verdicts in simulated sexual assault cases; women tend to be more sympathetic to the victim and treat the defendant more harshly (e.g. Fischer, 1991, 1997; George \& Martinez, 2002; Hammock \& Richardson, 1997; Jimenez \& Abreu, 2003; Johnson, Jackson, Gatto, \& Nowak, 1995; Koski, 2002; Schutte \& Hosch, 1997; Selby, Calhoun, \& Brock, 1977). This pattern characterizes both stranger (Hammock \& Richardson, 1997; Johnson et al., 1995; Schutte \& Hosch, 1997; Selby et al., 1977) and acquaintance rape cases (Fischer, 1991, 1997; Jimenez \& Abreu, 2003). We therefore included gender as a main effect variable and a possible moderator.

\section{Method}

Participants

Participants included 152 students (103 women, 49 men) recruited from undergraduate psychology courses at the University of Nebraska-Lincoln (UNL). Data were not collected 
on age and race/ethnicity; but nearly all UNL undergraduates are between ages 18 and 25, and the campus is $11 \%$ multicultural. Participants were at least 19 years old and therefore eligible for jury service in the state of Nebraska (although we did not check whether they met the residency and citizenship requirements, the majority of UNL students have their permanent residence in Nebraska, and there are few international students in the undergraduate student body). Participants received extra credit in return for their participation.

\section{Materials and design}

Participants read a three-page summary of a sexual assault trial. In all conditions, the summary described an encounter between the defendant and the alleged victim, which began at a large house party and ended at the woman's apartment, where the defendant allegedly raped her. The summary gave some description of the party the victim and defendant had attended, described the defendant as having been "drinking for most of the evening," stated that he had walked the victim home, and that they had had sex at her apartment. It summarized testimony from the alleged victim, her next-door neighbor (who escorted her to the hospital afterward), and the examining physician, who testified that "the results of the rape exam were inconclusive as to whether the sexual encounter was the result of force or not."

Participants were randomly assigned to one of the eight different conditions $(4 \times 2)$ of the trial summary, which varied solely in terms of the type of victim intoxication and the degree of closeness that existed between the victim and defendant. The trial summary stated that, at the time of the incident, the victim was (a) 20 years old and intoxicated as a result of alcohol use (illegal alcohol condition), (b) 21 years old and intoxicated as a result of alcohol use (legal alcohol condition), (c) 21 and intoxicated as a result of LSD use (LSD condition), or (d) 21 and sober. In all conditions where the victim was intoxicated, she had consumed the intoxicating substance knowingly and voluntarily to the point where she was "clearly intoxicated." In all conditions, the summary noted that "alcohol use in Nebraska is only legal for those aged 21 and older, whereas LSD use is illegal for the entire population." The victim's closeness with the defendant at the time of the incident was varied so that they either (a) were first-time acquaintances, or (b) had been dating each other for 3 months. Although in all conditions of the trial both the defendant and complainant agreed that sexual intercourse had occurred, the issue of consent was in dispute, a classic "he-said/she-said" case. These materials comprise evidence that would ordinarily be admissible in an acquaintance rape trial.

After the case summary, participants read standard jury instructions, which contained the legal definitions of first-degree sexual assault and consent. In the state of Nebraska, the crime of first-degree sexual assault is defined as "sexual penetration by a defendant (a) without consent of victim, or (b) knowing that a victim is mentally or physically incapable of resisting or appraising the nature of his or her conduct, or (c) when the actor is age 19 or older and the victim is less than age 16." The law states further that " without consent' means (a) the victim was compelled to submit due to the use of force or threat of force or coercion, or (b) the victim expressed a lack of consent through words, or (c) the victim expressed a lack of consent through conduct, or (d) the consent, if any was actually given, was the result of the actor's deception as to the identity of the actor or the nature or purpose of the act on the part of the actor."

\section{Procedure}

After reading and signing consent forms, participants were randomly assigned to one of the eight possible trial conditions. Booklets that contained jury instructions, the case summary, and the dependent measures were distributed to each participant. Participants were told "to imagine you are a juror in the case and to assess the responsibility and credibility of both the alleged victim and the defendant." They were then instructed to read the case summary and answer a series of questions based upon their impressions of the actors and actions involved in the case. Several of these questions were manipulation checks to ensure that participants correctly encoded the victim's substance use and the relationship between the victim and the defendant. Prior to providing their responses, participants were instructed that "Your decision about how to assess the guilt of the defendant should be based on the testimonies you were given within the trial summary. The law requires that your decision be made solely upon the evidence given to you. While you are the sole judge of the facts, you are required to accept the rules of law that you are given, whether you agree with them or not" (taken from actual pattern jury instructions).

Participants were tested in small groups but completed the materials individually. Upon completion of the experiment, participants were thanked and debriefed. The experiment took approximately $30 \mathrm{~min}$ to complete.

Dependent measures

\section{Credibility}

A series of five questions measured victim and defendant credibility (Wall \& Schuller, 2000). Specifically, these five items asked the participants to assess (a) the likelihood that the alleged victim communicated to the defendant that she did not agree to sexual relations, (b) the extent to which the defendant honestly believed the alleged victim was a willing participant, (c) the 
likelihood that the defendant physically forced the alleged victim, (d) the likelihood that the alleged victim was lying about the event, and (e) the degree to which the alleged victim was interested in having intercourse. Ratings were made on 7-point Likert-type scales (e.g., "very likely" to "very unlikely").

\section{Verdict}

Participants were asked to decide whether the defendant was guilty or not in regard to the first-degree sexual assault charge. They also indicated their level of confidence in this decision using a 7-point rating scale, ranging from 1 (very confident) to 7 (not confident).

\section{Attitude measures}

The Rape Myth Acceptance Scale (RMAS; Burt, 1980) measures attitudes toward rape, specifically with regard to topics such as gender role stereotyping, adversarial sexual beliefs, and acceptance of interpersonal violence. Participants responded to 19 statements on a 7-point rating scale that ranged from 1 (strongly agree) to 7 (strongly disagree) (e.g., "In the majority of rapes, the victim is promiscuous or has a bad reputation"). Lower scores on the RMA are indicative of greater acceptance of rape myths.

The Ambivalent Sexism Inventory (ASI; Glick \& Fiske, 1996) measures participants' level of both hostile (HS) and benevolent sexism (BS). Participants indicated their agreement/ disagreement with a series of 22 statements, on a 5-point rating scale (1; strongly disagree to 5; strongly agree). An example of a benevolent sexism item is "Despite accomplishment, men are incomplete without women"; "Women are too easily offended" is an example of a hostile sexism item.

The Cognitive Appraisal of Risky Events scale (CARE; Fromme et al., 1997) determines participants' beliefs about and perceptions of the negative and positive consequences that would likely occur if they engaged in a wide variety of risky activities, such as alcohol use, illicit drug use, aggressive behaviors, and risky sexual activities. Twenty-two activities were rated on 7-point scales (e.g., 1; not at all likely to 7; extremely likely), in terms of the activity's expected risk, expected benefit, and likelihood of personal involvement. Questions selected from the four (of six) subscales of the CARE measure relevant to the present research were included: Heavy Drinking (3 items; e.g., "Playing drinking games"), Illicit Drug Use (3 items; e.g., "Smoking marijuana"), Aggressive and Illegal Behaviors (10 items; e.g., "Getting into a fight or argument”), and Risky Sexual Activities (6 items; e.g., "Engaging in sexual activity with someone I recently met"). The subscales for High Risk Sports and Academic/Work Behaviors were not relevant to issues of substance use and sexual assault and were therefore omitted.
The three measures (expected risk, expected benefit, and likelihood of personal involvement) for each of the four assessed activities were highly correlated, so they were combined, yielding an aggregate risk-taking score for each activity.

\section{Results}

Main hypotheses were tested using three-way $(2 \times 4 \times 2)$ ANOVAs including participant gender, substance use condition, and relationship closeness as independent variables. Data from participants who missed more than one of the manipulation check questions were dropped, which left a final sample of 148 participants (100 women, $48 \mathrm{men}$ ). Due to a procedural error, 42 participants did not complete the verdict measure, which left data from 106 participants (69 women and 37 men) for that analysis.

\section{Credibility}

Participants answered five questions designed to capture broadly their perceptions of victim and perpetrator credibility. Because participants' responses to four of the questions (all except "the extent to which he believed she was a willing participant") were highly correlated, $r \mathrm{~s} \geq .28, p \mathrm{~s}<.001$, the answers to these questions were summed to create a single credibility index measure, $\alpha=.71$. High scores on the credibility index were indicative of higher levels of perceived victim credibility and, correspondingly, lower levels of perceived defendant credibility. Possible scores ranged from 4 to $28(M=18.48, S D=4.32)$.

There were main effects of substance use condition, $F(3$, $132)=5.60, p<.001, M S E=95.05$ (see Table 1), and gender, $F(1,132)=5.93, p<.05, M S E=100.65$. Post hoc (Tukey) tests showed that participants in the sober condition evaluated the victim as significantly more credible than did participants in the illegal alcohol and LSD conditions (see Table 1 for means). Credibility evaluations in the legal alcohol condition were intermediate and not significantly different from any of the other substance use conditions. In addition, women found the victim more credible $(M=19.03, S D=4.30)$ than men $\operatorname{did}(M=17.33, S D=4.17)$. There was no effect of relationship, nor were there any significant interactions, $F \mathrm{~S}<1.0$.

Verdict

Participants' verdicts were scored as 1 (guilty) or 2 (not guilty) and analyzed by three-way ANOVA (for the use of ANOVA with dichotomous data, see Lunney, 1970). There was a general difference across substance use conditions, $F(3,90)=$ $3.70, p<.05, M S E=0.83$ (see Table 1). A post hoc Tukey test showed that participants in the sober condition were sig- 
Table 1 Verdicts and credibility judgments as a function of victim substance use

\begin{tabular}{lll}
\hline Substance use condition & Victim credibility & Guilty verdicts $(\%)$ \\
\hline Sober & $20.76^{\mathrm{a}}$ & $87.0^{\mathrm{a}}$ \\
Legal alcohol & $18.85^{\mathrm{a}, \mathrm{b}}$ & $42.9^{\mathrm{b}}$ \\
LSD & $17.58^{\mathrm{b}}$ & $57.1^{\mathrm{a}, \mathrm{b}}$ \\
Illegal alcohol & $17.03^{\mathrm{b}}$ & $44.4^{\mathrm{b}}$ \\
\hline
\end{tabular}

Note. Within a column, means with different superscripts were significantly different from one another (Tukey, $p<.05$ ). Victim credibility was a composite measure (see text), where higher values indicated higher perceived credibility.

nificantly more likely to find the defendant guilty than were participants in the illegal and legal alcohol conditions. The LSD condition was intermediate and not significantly different from any of the other substance use conditions. Although verdict decisions did not demonstrate a significant gender difference, $F(1,90)=2.28, p=.14$, there was a slightly greater tendency for women than for men to find the defendant guilty $(60.9 \%$ vs. $48.6 \%)$. There was no effect of relationship, nor were there any significant interactions, $F \mathrm{~s}<2.84$.

\section{Regression analyses}

Our third hypothesis predicted that participants' attitudes toward women, rape, and risky behaviors would be associated with their credibility judgments and verdicts. Participants' credibility ratings were regressed onto their RMA, HS, and BS scores, as well as their attitudes toward drinking, drug use, aggression, and risky sexual activities. The model explained a significant amount of the variance in credibility judgments, $R^{2}=.17, p<.001$; but RMA scores were the only significant predictor, $\beta=.28, p<.01$.

None of the attitudinal measures was significantly correlated with verdicts. Participants' credibility judgments were positively correlated with their verdict decisions, $r=-.63, p<$ .001 , which demonstrates that participants who perceived the victim as more credible (and the defendant as less credible) were more likely to find the defendant guilty.

\section{Discussion}

This experiment demonstrated that victim substance use can affect how potential jurors perceive the dynamics involved in a sexual assault case. Research findings supported our main hypothesis, as mock jurors' perceptions of credibility and verdicts were affected by the victim's substance use. Participants in the sober condition viewed the victim as significantly more credible than did those participants in both the illegal alcohol and LSD intoxication conditions, and guilty verdicts were most frequent in the sober condition. These findings are consistent with previous alcohol-related research (Hammock \& Richardson, 1997; Schuller \& Wall, 1998), and they extend these findings to other types of substances. Despite the differential perception of alcohol and other psychoactive substances (Weisheit \& Johnson, 1992), alcohol and LSD exerted similar effects in the present context.

Contrary to previous findings (Hammock \& Richardson, 1997), participants' judgments did not reflect a significant interaction between substance use and relationship closeness. Other research also suggests that this variable might not be as important as is commonly assumed (Koski, 2002). Various aspects of a prior acquaintanceship (e.g., whether or not there is a romantic involvement, length and seriousness of a dating relationship, degree of attraction) might matter more than the new acquaintance/dating distinction manipulated here. Relational history might also moderate the effect of some factors more than others (Schuller \& Klippenstine, 2004).

Our findings did support the findings of previous research by demonstrating that jurors' perceptions of victim credibility were affected by participant gender (e.g., Fischer, 1991, 1997 Hammock \& Richardson, 1997; Jimenez \& Abreu, 2003; Johnson et al., 1995; Koski, 2002; Schutte \& Hosch, 1997). Women rated the victim as significantly higher in credibility than men did. Gender did not interact significantly with the manipulated variables. Although there were no a priori reasons to suspect that it would, it is possible that the relatively small number of male participants did not confer adequate power to detect such interactions.

Participants' attitudes were related to their decisions as well but only with respect to RMA. Participants who were low in RMA perceived the victim more favorably. The failure of sexist attitudes, in particular, to predict participants' judgments about the case is inconsistent with previous research (e.g., Abrams et al., 2003; Viki et al., 2004). Attitudes are relatively poor predictors of jurors' decisions in general (Fulero \& Penrod, 1990), except when they are specifically relevant to the case (Moran, Cutler, \& De Lisa, 1994). With the exception of RMA, which is clearly and directly related to issues raised in a sexual assault trial, the attitudes assessed in the present study might be too broad to demonstrate a strong relationship to participants' judgments.

An awareness of these findings could have significant implications within the legal system. Trial lawyers ought to be aware of the potential influence a victim's substance use can have on jurors' decision-making in sexual assault cases. In addition, our results support the utility of using RMA as an effective tool during voir dire to measure which potential jurors might hold specific, stereotyped beliefs about rape. These attitudes significantly predict people's evaluations of others who are involved in coercive sexual encounters (Lonsway \& Fitzgerald, 1994). 
Future directions and limitations

Future researchers should attempt to replicate the present findings in a more naturalistic trial and with mock juries rather than with individual mock jurors. Real jurors see and hear testimony at trial; they do not (with rare exceptions) read it. Although the jury simulation literature has documented few differences as a function of the trial presentation medium (Bornstein, 1999), it is possible that the results would differ with "live" actors. The testimony of a flesh-and-blood victim would naturally be much more powerful than a mere written description; however, it is impossible to predict whether more realistic materials would heighten, diminish, or not alter the effect of the victim's substance use.

Although jury verdicts are usually determined by the distribution of individual verdict preferences prior to deliberation, there is reason to believe that deliberation can influence jury outcomes in certain situations (Devine, Clayton, Dunford, Seying, \& Pryce, 2001; Koski, 2002). For example, Fischer (1997) found that although individual female mock jurors consistently reached guilty verdicts in rape trials more often than individual male mock jurors did, this difference did not appear in deliberating juries until women comprised an overwhelming majority (i.e., 10-2) of the jury. Group decision-making might also discourage participants from relying on their own stereotypic beliefs in determining a verdict, thus diminishing the strength of the relationship between RMA and verdicts in sexual assault cases. Finally, from a public policy perspective, it is generally worthwhile to replicate results from individuals with results from deliberating groups (Bornstein, 1999; Diamond, 1997).

The amount of alcohol consumed by both perpetrators and victims of sexual assault varies widely and affects the incident's outcome on multiple dimensions (e.g., Abbey et al., 2002; Testa, 2004; Ullman et al., 1999). For example, greater victim intoxication is associated with less resistance; this effect may be direct (Abbey et al., 2002)or indirect (Ullman et al., 1999). The materials in the present study (in the substanceuse conditions) stated that the victim was "clearly intoxicated" but did not otherwise address her level of functioning. "Intoxication" is a vague enough term that its implications for the victim's functioning, such as her ability to resist or appraise the nature of her conduct, might be somewhat ambiguous. Future researchers should attempt to tease apart the contributions to participants' judgments of substance use, per se, versus its effects on the alleged victim's (or perpetrator's) functioning, perhaps by including testimony from other witnesses on how the principal actors were behaving prior to the assault. The manipulation of the legality of the victim's alcohol consumption also introduced a slight confound with respect to her age (20 in the illegal condition versus 21 in the legal condition). Although this confound was unavoidable and unlikely to exert an effect, it is nonetheless possible that impressions of 20-and 21-year-old sexual assault victims would vary.

The present study held the perpetrator's substance use constant. Previous research, which has focused on alcohol, has shown that people's perceptions of sexual assault are influenced in a complex manner by both the victim's and the perpetrator's substance use (Wall \& Schuller, 2000). The relationship between alcohol and sexual violence is not as strong for perpetrators as it is for victims (Testa, 2004), but future researchers should nonetheless explore the effect on mock jurors' perceptions of victim and perpetrator substance use in combination, especially for substances other than alcohol. LSD is but one among many types of illegal drugs that might be implicated in sexual violence. Given that attitudes toward different drugs vary widely (Stylianou, 2002; Weisheit \& Johnson, 1992), other drugs might operate the same or differently in the context of a sexual assault trial. Future researchers should also attempt to generalize the present findings to jurors' judgments in stranger rape cases, as the same variables (especially attitudes related to RMA and sexism) do not necessarily have the same effects on evaluations of stranger rape and acquaintance rape (Frese et al., 2004; Viki et al., 2004).

In conclusion, there are many variables to consider in an examination of how jurors make decisions in sexual assault cases, including various aspects of the victim's and the perpetrator's behavior, as well as jurors' gender, attitudes, and expectancies. The present findings were consistent with previous research that has shown the importance of jurors' attitudes (especially RMA) and gender on their evaluation of rape cases (e.g., Deitz et al., 1984; Fischer, 1991; Koski, 2002; Lonsway \& Fitzgerald, 1994; Wall \& Schuller, 2000). In the present study, the victim's substance use had an effect as well, as the intoxicated victim - whether from legal alcohol use, illegal alcohol use, or a less socially acceptable drug such as LSD - was perceived less favorably than the sober victim. At trial, as elsewhere (Leigh et al., 1992), different standards appear to exist for men and women in regard to how others perceive their substance use in sexual situations.

Acknowledgments: We thank Dick Dienstbier for his helpful comments and advice on the project. This article is based on an honors thesis conducted by the first author, under supervision of the second author. An earlier version of this article was presented at the 2004 meeting of the American PsychologyLaw Society in Scottsdale, Arizona.

\section{References}

Abbey, A. (2002). Alcohol-related sexual assault: A common problem among college students. Journal of Studies on Alcohol, S14, S118-S128. 
Abbey, A., Clinton, A. M., McAuslan, P. Zawacki, T., \& Buck, P. O. (2002). Alcohol-involved rapes: Are they more violent? Psychology of Women Quarterly, 26, 99-109.

Abbey, A., McAuslan, P., Ross, L. T., \& Zawacki, T. (1999). Alcohol expectancies regarding sex, aggression, and sexual vulnerability: Reliability and validity assessment. Psychology of Addictive Behaviors, 13, 174-182.

Abbey, A., Zawacki, T., Buck, P. O., Clinton, A. M., \& McAuslan, P. (2004). Sexual assault and alcohol consumption: What do we know about their relationship and what types of research are still needed? Aggression and Violent Behavior, 9, 271-303.

Abrams, D., Viki, G. T., Masser, B., \& Bohner, G. (2003). Perceptions of stranger and acquaintance rape: The role of benevolent and hostile sexism in victim blame and rape proclivity. Journal of Personality and Social Psychology, 84, 111-125.

Bornstein, B. H. (1999). The ecological validity of jury simulations: Is the jury still out? Law and Human Behavior, 23, 75-91.

Burt, M. R. (1980). Cultural myths and supports for rape. Journal of Personality and Social Psychology, 38, 217-230.

Copenhaver, S., \& Grauerholz, E. (1991). Sexual victimization among sorority women: Exploring the link between sexual violence and institutional practices. Sex Roles, 24, 31-41.

Deitz, S. R., Littman, M., \& Bentley, B. J. (1984). Attribution of responsibility for rape: The influence of observer empathy. Sex Roles, 10, 261-280.

Devine, D. J., Clayton, L. D., Dunford, B. B., Seying, R., \& Pryce, J. (2001). Jury decision making: 45 years of empirical research on deliberating groups. Psychology, Public Policy, and Law, 7, 622-727.

Diamond, S. S. (1997). Illuminations and shadows from jury simulations. Law and Human Behavior, 21, 561-571. Doweiko, H. E. (1996). Concepts of chemical dependency (3d ed.). Pacific Grove, CA: Brooks/Cole.

Fischer, G. J. (1991). Cognitive predictors of not-guilty verdicts in a simulated acquaintance rape trial. Psychological Reports, 68, 1199-1206.

Fischer, G. J. (1997). Gender effects on individual verdicts and on mock jury verdicts in a simulated acquaintance rape trial. Sex Roles, 36, 491-501.

Frese, B., Moya, M., \& Megías, J. L. (2004). Social perception of rape: How rape myth acceptance modulates the influence of situational factors. Journal of Interpersonal Violence, 19, 143-161.

Fromme, K., Katz, E. C., \& Rivet, K. (1997). Outcome expectancies and risk-taking behavior. Cognitive Therapy and Research, 21, 421-442.

Fulero, S. M., \& Penrod, S. D. (1990). Attorney jury selection folklore: What do they think and how can psychologists help? Forensic Reports, 3, 233-259.

George, W. H., Lehman, G. L., Cue, K. L., \& Martinez, L. J. (1997). Postdrinking sexual inferences: Evidence for linear rather than curvilinear dosage effects. Journal of Applied Social Psychology, 27, 629-648.

George, W. H., \& Martinez, L. J. (2002). Victim blaming in rape: Effects of victim and perpetrator race, type of rape, and participant racism. Psychology of Women Quarterly, 26, 110-119.

Glick, P., \& Fiske, S. T. (1996). The Ambivalent Sexism Inventory: Differentiating hostile and benevolent sexism. Journal of Personality and Social Psychology, 70, 491-512.

Hammock, G. S., \& Richardson, D. R. (1997). Perceptions of rape: The influence of closeness of relationship, intoxication, and sex of participant. Violence and Victims, 12, 237-246.

Jimenez, J. A., \& Abreu, J. M. (2003). Race and sex effects on attitudinal perceptions of acquaintance rape. Journal of Counseling Psychology, 50, 252-256.

Johnson, J. D., Jackson, L. A., Gatto, L., \& Nowak, A. (1995). Differential male and female responses to inadmissible sexual history information regarding a rape victim. Basic and Applied Social Psychology, 16, 503-513.

Kilpatrick, D. G., Acierno, R., Resnick, H. S., Saunders, B. E., \& Best, C. L. (1997). A 2-year longitudinal analysis of the relationships between violent assault and alcohol and drug use in women. Journal of Consulting and Clinical Psychology, 65, 834-847.

Koski, D. D. (2002). Jury decisionmaking in rape trials: A review and empirical assessment. Criminal Law Bulletin, 38, 21-159.

Leigh, B. C., Aramburu, B., \& Norris, J. (1992). The morning after: Gender differences in attributions about alcohol-related sexual encounters. Journal of Applied Social Psychology, 22, 343-357.

Lonsway, K. A., \& Fitzgerald, L. F. (1994). Rape myths: In review. Psychology of Women Quarterly, 18, 133-164.

Lunney, G. H. (1970). Using analysis of variance with a dichotomous dependent variable: An empirical study. Journal of Educational Measurement, 7, 263-269.

Marx, B. P., Nicols-Anderson, C., Messman-Moore, T., Miranda, R. J., \& Porter, C. (2000). Alcohol consumption, outcome expectancies, and victimization among female college students. Journal of Applied Social Psychology, 30, 1056-1070.

Moran, G., Cutler, B. L., \& De Lisa, A. (1994). Attitudes toward tort reform, scientific jury selection, and juror bias: Verdict inclination in criminal and civil trials. Law \& Psychology Review, 18, 309-328.

Schuller, R. A., \& Klippenstine, M. A. (2004). The impact of complainant sexual history evidence on jurors' decisions: Considerations from a psychological perspective. Psychology, Public Policy, and Law, 10, 321-342.

Schuller, R. A., \& Wall, A. M. (1998). The effect of defendant and complainant intoxication on mock jurors' judgments of sexual assault. Psychology of Women Quarterly, 22, 555-572.

Schutte, J. W., \& Hosch, H. M. (1997). Gender differences in sexual assault verdicts. Journal of Social Behavior and Personality, 12, 759-772.

Seifert, S. A. (1999). Substance use and sexual assault. Substance Use and Misuse, 34, 935-945.

Selby, J. W., Calhoun, L. G., \& Brock, T. A. (1977). Sex differences in the social perception of rape victims. Personality and Social Psychology Bulletin, 3, 412-415.

Stylianou, S. (2002). Control attitudes toward drug use as a function of paternalistic and moralistic drug use. Journal of Drug Issues, 32, 119-153. 
Taylor, T. S., \& Hosch, H. M. (2004). An examination of jury verdicts for evidence of a similarity-leniency effect, an out-group punitiveness effect or a black sheep effect. Law and Human Behavior, 28, 587-598.

Testa, M. (2004). The role of substance use in male-to-female physical and sexual violence: A brief review and recommendations for future research. Journal of Interpersonal Violence, 19, 1494 1505.

Testa, M., \& Parks, K. A. (1996). The role of women's alcohol consumption in sexual victimization. Aggression and Violent Behavior, 1, 217-234.

Tyler, K. A., Hoyt, D. R., \& Whitbeck, L. B. (1998). Coercive sexual strategies. Violence and Victims, 13, 47-61.

Ullman, S. E., Karabatsos, G., \& Koss, M. P. (1999). Alcohol and sexual assault in a national sample of college women. Journal of Interpersonal Violence, 14, 603-625.
Viki, G. T., Abrams, D., \& Masser, B. (2004). Evaluating stranger and acquaintance rape: The role of benevolent sexism in perpetrator blame and recommended sentence length. Law and Human Behavior, 28, 295-303.

Wall, A. M., \& Schuller, R. A. (2000). Sexual assault and defendant/ victim intoxication: Jurors' perceptions of guilt. Journal of Applied Social Psychology, 30, 253-274.

Weisheit, R. A., \& Johnson, K. (1992). Exploring the dimensions of support for decriminalizing drugs. Journal of Drug Issues, 22, $53-75$.

Zawacki, T., Abbey, A., Buck, P. O., McAuslan, P., \& Clinton-Sherrod, A. M. (2003). Perpetrators of alcohol-involved sexual assaults: How do they differ from other sexual assault perpetrators and nonperpetrators? Aggressive Behavior, 29, 366-380. 